\title{
Uso de medicamentos psicotrópicos e repercussões existenciais para usuários de um CAPS II
}

Deisiluce Miron Cavalcante. Psicóloga Clínica

Barbara Eleonora Bezerra Cabral. Universidade Federal do Vale do São Francisco

\section{Resumo}

A medicalização, compreendida como fenômeno social constituído pela primazia da racionalidade biomédica, vem sendo intensamente estudada na contemporaneidade. Nesse contexto, a pesquisa objetivou compreender de que modos o uso de psicotrópicos repercute na vida de usuários de um CAPS II. Assumiu caráter qualitativo, recorrendo à cartografia como modo de investigação. A produção dos dados ocorreu através da colheita de depoimentos dos usuários - pelo estímulo à narração de sua experiência com o uso da medicação -, tanto individual como coletivamente, e da escrita de diários de campo. A análise ocorreu pela interlocução com o material colhido, mediante leituras dos depoimentos e diários, revelando-se aspectos cruciais. Dos resultados, destaca-se a posição central da medicação no tratamento, a relação ambivalente dos usuários com o seu uso e o preconceito sofrido. Indica-se a necessidade do reconhecimento da singularidade dos usuários no planejamento e efetivação de projetos terapêuticos, reposicionando criticamente a supremacia do saber biomédico.

Palavras-chave: medicalização; psicotrópicos; saúde mental.

\section{Abstract}

Psychotropic drug use and repercussions existential for users of a Caps II. The medicalization, a social phenomenon constituted by the primacy of biomedical rationality, has been intensively studied. Therefore, the study aimed to understand how the use of psychotropic medication affects the lives of users of a CAPS II. Assuming a qualitative approach, cartography was taken as research method. Data production occurred from the harvest of narratives of the users about their experience with the use of medication, individually and collectively, and the writing of field diaries. The analysis was based on the interlocution with the material collected by its systematic reading, which revealed important aspects. Among the results, one finds the central position of the medication in the treatment, the ambivalent relationship of the users with the medication and the prejudice suffered. This indicates the importance of acknowledging the singularity of the users in the planning and execution of therapeutic projects and promoting a critical repositioning of the biomedical knowledge supremacy.

Keywords: medicalization; psychotropic; mental health.

\section{Resumen}

Uso de fármacos psicotrópicos y repercusiones existenciales para los usuarios de un CAPS II. La medicalización, un fenómeno social formado a partir de la primacía de la racionalidad biomédica, ha sido estudiada intensamente en la actualidad. Así, la investigación ha buscado comprender como el uso de drogas psicotrópicas afecta la vida de los usuarios de un CAPS II. Se ha tomado una perspectiva cualitativa, utilizando la cartografía. Producción de datos ha ocurrido a través de la cosecha de narrativas de los usuários, individualmente y colectivamente, y la escritura de diarios de campo. El análisis se produjo por la interlocución con el material recogido, revelando aspectos cruciales. Los principales resultados destacan la posición central de la medicación en el tratamiento, la relación ambivalente con su uso y el prejuicio sufrido, lo que indica la importancia de reconocer la singularidad de los usuarios en la planificación y ejecución de proyectos terapêuticos y del reposicionamento crítico de la supremacía del saber biomedico.

Palabras clave: medicalización; psicotrópico; salud mental. 
Segundo Conrad (1992), a medicalização é um processo sociocultural, que consiste em descrever um problema utilizando termos médicos, representado por uma linguagem médica e sendo tratado a partir de intervenções médicas. Assim, processos naturais da vida passaram a ser medicalizados, tais como a vivência da sexualidade, parto, desenvolvimento infantil, menopausa, desconforto menstrual, envelhecimento, morte, conflitos familiares e interpessoais, dificuldades de aprendizagem, entre outros.

Gaudenzi e Ortega (2011) salientam que a expressão medicalização surgiu no século XX, no final dos anos 60, referindo-se aos modos de apropriação da vida humana pelas práticas médicas que, por sua vez, têm o poder de transformar aspectos básicos da vida em patologias. Nesse processo de medicalização, o uso dos fármacos costuma ser o "recurso terapêutico mais utilizado" (Ferrazza, Luzio, Rocha, \& Sanches, 2010, p. 382), devendo-se atentar, contudo, à compreensão de que esse é apenas um dos aspectos de um fenômeno reconhecidamente complexo.

Santos (2012) ressalta que o tema da medicalização tem sido considerado um problema de saúde pública e, seguramente, uma de suas facetas mais preocupantes é o aumento vertiginoso do uso de medicamentos e seu uso irracional. De acordo com dados da Organização Mundial de Saúde [OMS] (1946), a população brasileira tem estado entre os maiores consumidores de medicamentos do mundo.

$\mathrm{Na}$ área da Saúde Mental, esse problema também assume relevância e gravidade, especialmente por se constituir um campo de disputas de modelos de cuidado, em que a racionalidade psiquiátrica revela forte poder. Considerando que há uma produção de verdades acerca do sofrimento psíquico a partir do discurso médico e que a prescrição medicamentosa se incorpora, destacadamente, no repertório das intervenções médicas - em geral associadas a um amplo leque de diagnósticos -, a medicação sobressai como principal estratégia terapêutica.

Ressalta-se a concepção foucaultiana de verdade: "um conjunto de procedimentos regulados para a produção, a lei, a repartição, a circulação e o funcionamento de enunciados" (Foucault, 1979, p. 14), relacionando-se diretamente ao sistema de poder que a produz, reproduz e a apoia, de caráter disciplinar. A instituição da psiquiatria e do hospício dependeram da produção da verdade do louco como "doente mental".
Importa atentar à força crescente da racionalidade biomédica, que se respalda cientificamente em estudos no campo da Genética ou das Neurociências (Caponi, 2014; Neto \& Caponi, 2010). Trata-se de algo em curso, ainda que diversas outras racionalidades médicas já tenham sido reconhecidas na contemporaneidade, a exemplo da homeopatia, ayurvédica, medicina tradicional chinesa, entre outras (Luiz \& Barros, 2012).

Pode-se compreender que se o sujeito com transtorno psíquico experimenta a medicação como único ou mais importante - recurso utilizado em seu processo terapêutico, isso possivelmente conduzirá ao silenciamento do sintoma, sem uma devida investigação, de ordem clínica, sobre sua origem, que envolva aspectos que extrapolem o orgânico e podem ser relevantes para o sujeito se situar em sua lida com a condição de sofrimento. Calando-se o sintoma, simplesmente, cala-se o sujeito em questão, operando-se uma simplificação ou redução de seus processos subjetivos, sempre singulares, de pessoa vivente no mundo.

Para Onocko-Campos e Gama (2008), a medicação pode ser empregada como uma forma de apaziguamento do sujeito, deixando-o passivo. Isto interfere em seu progresso terapêutico, repercutindo na sua reabilitação social, em aspectos como a sua não responsabilização por um problema que é seu, dado a possível melhora ser atribuída somente ao medicamento, bem como a sua institucionalização, pelo estabelecimento de um vínculo de dependência com o dispositivo terapêutico em que se insere.

Ferrazza et al. (2010) apontam que os medicamentos psicotrópicos vêm sendo empregados na intervenção de qualquer mal-estar do indivíduo, quer em momentos de tristeza, desamparo, insegurança, angústia, ansiedade ou até mesmo na ausência de felicidade. Por vezes se revela nisso um processo de psiquiatrização da vida social, transformando todo e qualquer mal-estar em doença, valorizando a concepção biológica do sofrimento psíquico e incentivando, assim, processos terapêuticos baseados essencialmente em recursos químicos. Segundo Tesser e Barros (2008), decorre disso uma redução das possibilidades terapêuticas, com a desvalorização dos modos de vida, princípios e fatores subjetivos e sociais envolvidos no processo saúde-doença em curso na existência da pessoa.

Nessa perspectiva, Caponi $(2009,2012)$ salienta que, entre o normal e o patológico, as fronteiras parecem estar se tornando cada vez mais indeterminadas, 
móveis e instáveis, de modo que a medicalização dos comportamentos rotulados como anormais passou a se estender praticamente para todos os domínios da existência humana, em um processe que denomina de ampliação da psiquiatria. Em sintonia com essa avaliação, Severo e Dimenstein (2009, p. 60) afirmam que, "cada vez mais vai se patologizando aquilo que escapa aos modos instituídos de viver e criando-se novas categorias diagnósticas, sempre mais flexíveis, mais permeáveis, com poder de capturar as mais tênues diferenças com relação à norma". Nesse cenário, o mal-estar e o sofrimento, de qualquer ordem, devem ser abolidos, a qualquer preço. A definição de saúde como um estado de completo bem-estar biopsicossocial (OMS, 1946) parece ser tomada como ideal, nesse contexto. Com isso, Dantas (2009) ressalta que a medicalização da vida tem se tornado o caminho mais curto e rápido para diminuir o sofrimento psíquico, extinguindo, assim, as inquietações cotidianas.

Em meio a essa discussão, a pesquisa buscou compreender como o uso de medicamentos psicotrópicos, como recurso terapêutico, repercute na vida de usuários de um Centro de Atenção Psicossocial (CAPS II), localizado em um município do interior de Petrolina (PE), que funciona como referência para a atenção à saúde mental na cidade. Assim, atentou-se a como a prescrição e utilização contínua desses medicamentos podem afetar os modos como o sujeito se conduz em seu processo existencial, como protagonista de sua vida.

Realça-se a relevância social e científica do estudo pela importância do fenômeno da medicalização na sociedade contemporânea e por pautar-se na perspectiva de contribuir para a compreensão das repercussões do emprego de medicamentos psicotrópicos no âmbito da Rede de Atenção Psicossocial/RAPS. Seu intuito, longe de desqualificar o uso dos psicofármacos, é contribuir para repensá-lo ou redimensioná-lo no contexto de práticas terapêuticas voltadas à produção de saúde e a valorização do sujeito.

\section{Método}

O estudo, de caráter qualitativo, foi realizado em um CAPS II, caracterizando-se como uma pesquisa-intervenção e assumindo, portanto, a implicação do pesquisador no campo (Passos \& Barros, 2009). Utilizamos o método cartográfico, experimentando o processo de produção da pesquisa no contato direto com os sujeitos, no território em que estão inseridos (Kastrup, 2009).
Por quatro meses, período da imersão em campo, os diários de campo foram escritos pela pesquisadora principal, que atuava também como discente do Estágio Profissionalizante do Curso de Psicologia no cenário da pesquisa. Os diários de campo extrapolavam a mera descrição dos fatos ocorridos, privilegiando o registro da experiência vivida pela pesquisadora e, portanto, revelando momentos de reflexão e interpretação dessa experiência de imersão cartográfica.

Além da escrita dos diários, recorremos às narrativas de usuários do serviço, compreendidos como interlocutores, forjando-se, então, o que se chamará de "matéria-prima", fruto da colheita de "dados". A definição dos interlocutores ocorreu espontaneamente, mediante a manifestação do interesse de usuários que frequentavam o serviço diariamente.

De acordo com Dutra (2002), colher narrativas permite ao pesquisador se aproximar da experiência tal como é vivida pelo narrador, reconhecendo os valores, impressões e percepções presentes na experiência narrada ao pesquisador, o qual irá escutar, construindo compreensões segundo a sua interpretação.

Os depoimentos dos interlocutores foram colhidos ao longo de dois meses, em conversas individuais. Dez usuários se disponibilizaram a tais conversas, as quais foram gravadas com a devida autorização prévia, partindo de uma pergunta provocadora: "Você poderia me contar como é sua experiência com o uso da medicação no seu tratamento?". A narração, como o processo de contar algo que se vive, ia, então, desdobrando-se, de acordo com o que o interlocutor queria e se sentia à vontade para falar. A pesquisadora se posicionava no sentido de estimular tal comunicação da experiência relativa ao tema da pesquisa.

Tendo em vista as atividades rotineiramente desenvolvidas no CAPS, consideramos pertinente realizar uma atividade voltada ao tema da pesquisa no grupo semanal facilitado por profissionais de Psicologia, que abordava os mais variados temas. A atividade objetivou promover uma discussão, em grupo, sobre a repercussão do uso de medicamentos psicotrópicos no cotidiano dos usuários, nos diversos aspectos. Assim, o que foi produzido nesse contexto grupal acabou por também integrar a matéria-prima a que se recorreu para compor as compreensões resultantes da pesquisa.

A análise também tomou como referência o próprio método cartográfico, valorizando-se o que foi construído na imersão em campo, na relação com os interlocutores e com as demais pessoas que circulavam no 
serviço. Esse é um dos métodos de pesquisa em que se exercita a integração dos diversos passos da produção de conhecimento, com atenção a cada efeito da pesquisa ainda em campo, de modo que o processo de análise já se inicia ali, sendo esse trabalho "a um só tempo o de descrever, intervir e criar efeitos-subjetividade" (Passos \& Barros, 2009, p. 27). Desse modo, consideramos que o processo interpretativo ocorreu desde a escrita dos diários e as conversas com usuários, até a releitura do material registrado e transcrito, engendrando-se uma produção de compreensões na interlocução com a matéria-prima.

Tal interlocução deu a ver pontos que se destacaram na leitura sistemática da matéria-prima, subsidiando o delineamento de eixos de análise ou dimensões que concentram os aspectos analisados como axiais para responder à questão de pesquisa. Cabe esclarecer que os realces foram se revelando na conexão com os objetivos da pesquisa, de forma que as dimensões apresentadas e discutidas a seguir revelam um modo possível de comunicar o que se produziu de compreensões, como resultados do estudo.

\section{Resultados e discussão}

Duas dimensões foram delineadas a partir do processo interpretativo: (a) A experiência dos usuários na relação com o uso da medicação, que aborda as repercussões biopsicossociais do uso do medicamento psicotrópico na existência do sujeito diagnosticado com transtorno psíquico, em processo terapêutico; e (b) A importância de atuação terapêutica sensível à singularidade do usuário, que indica a pertinência de uma reflexão acerca da atitude de trabalhadores no reconhecimento (ou não) do protagonismo do usuário no seu processo terapêutico. Consideramos que tais dimensões estão intimamente conectadas, sendo mutuamente transversais e articulando, cada uma, diversos realces da matéria-prima colhida.

\section{A Experiência dos Usuários na Relação com o Uso da Medicação}

Como primeiro destaque nessa dimensão está a posição central que a medicação assume no processo terapêutico e na própria vida desses sujeitos, revelando-se nisso um paradoxo. Mesmo percebendo o uso dos medicamentos psicotrópicos como a parte principal do seu tratamento, os usuários indicaram uma profusão de efeitos adversos no corpo, além de um atravessamento significativo desse uso no seu modo de estar no mundo.
Compreendemos que os olhares dos usuários a respeito do assunto apresentaram-se embasados, sobretudo, em uma perspectiva biológica, de modo que os aspectos que se sobressaíram nas suas narrativas estavam relacionados, marcantemente, aos efeitos físicos que o uso da medicação provoca.

Percebemos que isto pode indicar que o tratamento oferecido continua se centrando nos princípios da racionalidade biomédica que, logicamente, localiza a medicação no centro do tratamento. Tais efeitos físicos destacados interferem diretamente não só corporalmente, mas também na condição existencial, reverberando no cotidiano e nos modos de viver. Essa centralidade do uso da medicação no tratamento também foi identificada em estudo de Bezerra, Jorge, Gondim, Lima e Vasconcelos (2014), que aponta um processo terapêutico nos serviços de saúde mental reduzido ao uso de psicofármacos para condições de sofrimento psíquico que, por vezes, remetem a problemas socioeconômicos.

Nesse contexto, a discussão sobre as Racionalidades Médicas, que tem no pensamento de Madel Luz uma importante âncora, ganha vulto diante da necessidade de repensar o saber/fazer das práticas de saúde adotadas, defendendo a existência de distintas racionalidades médicas nos modos de cuidado e pondo em xeque a hegemonia biomédica na sociedade atual.

Outro ponto fundamental relaciona-se ao fato de que, apesar de os usuários reconhecerem o efeito positivo que a medicação possui no controle e diminuição dos sintomas, a dependência e os efeitos colaterais que o medicamento provoca são apontados como pontos negativos do seu uso, expressando-se certa ambivalência dos usuários em relação ao uso das medicações, conforme indicado no fragmento abaixo:

Com a medicação é melhor por uma parte, porque não existe crise e choro, eu me alimento e, por outra, é ruim, porque deixa a gente dopada, eu fico tonta. [...] A gente fica sem coragem; vou arrumar a casa, eu acho que a casa fica grande, quanto mais eu faço, eu olho pra trás e parece que eu não fiz nada... Dá vontade de chorar! (Usuário 9).

Essa ambivalência na relação desses sujeitos com o uso do medicamento se acentua quando expressam a necessidade e obrigatoriedade do uso, afirmando, ao mesmo tempo, o quanto se sentem aprisionados com isso:

Com o medicamento eu me dou bem, porque na hora que eu tomo ele, eu fico bem. Agora se eu parar de tomar dá a depressão. Tem dia que eu 
fico pensando 'Meus Deus é tão ruim tomar o Diazepam, e sou obrigado a tomar'. Eu já tentei vê se passava uma noite sem dormir com o Diazepam, mas eu tenho que levantar e tomar [...] Já tá com quatro anos que eu tomo, só que agora o Diazepam tá que eu não durmo mais como antigamente, acho que a gente vai se acostumando. (Usuário 3).

Carvalho, Costa e Fagundes (2006) ressaltam que o uso prolongado de psicofármacos, especialmente os benzodiazepínicos, podem causar tolerância e dependência; por isso, é necessária uma atenção ao tempo de uso contínuo e às consequências para o sujeito. Em relação a esse aspecto, Bezerra, Morais, Paula, Silva e Jorge (2016) salientam que o uso da medicação é uma decisão que deve ser discutida entre o profissional e o usuário, na negociação de estratégias terapêuticas para seu processo de cuidado. Assim, defendem que o uso não deveria ser imposto ou posto como principal fator para superar a condição apresentada e melhorar a vida, entrando no processo de construção coletiva do projeto de cuidado, disponibilizando-se as informações necessárias.

Em alguns depoimentos, os usuários destacaram a ineficácia do medicamento no controle dos sintomas, tendo que encontrar estratégias, por si só, para lidar com eles:

A medicação, posso dizer a você que controlar, não controla não, porque ontem à noite eu estava tendo alucinação do mesmo jeito, entendeu? Eu tava ouvindo barulho dentro da minha casa. Eu sempre tento driblar! Quando não são barulhos, são visões de pessoas, quando eu estou caminhando na rua. [...] Quando eu escuto esses baruIhos, eu não dou atenção (Usuário 2).

A esse respeito, Rozemberg (1994, p.04) salienta que mesmo a medicação não tendo a eficácia esperada, o usuário adota-a como uma espécie de "prótese química", preocupando-se em não ficar sem a medicação e ter que lidar com seus sintomas agravados. O próprio fato de a medicação estar chegando ao fim pode desencadear sintomas que, geralmente, são vistos como remissão ao estágio inicial da doença. $\mathrm{O}$ autor destaca também que esse é um dos aspectos que contribui para que o usuário assuma uma identidade de "doente crônico", devido à utilização indefinida da medicação. Tal recorte denuncia, ainda, a posição central que o medicamento possui no tratamento dos usuários, posta aqui em análise.
Em consonância a isto, evidenciaram-se queixas variadas relativas aos efeitos colaterais nas narrativas: sono excessivo, comprometimento da memória, tremores, dormência no corpo, falta de ânimo para a realização das atividades diárias e diminuição do desejo sexual. Tais fatores, muitas vezes, implicam prejuízos físicos e psíquicos, reverberando no seu cotidiano e autonomia.

Dos efeitos adversos, o constante estado de sonolência dos usuários era visivelmente percebido na imersão em campo, fato comumente indicado como justificativa, pelos usuários, para a não participação nas atividades terapêuticas propostas no serviço. De acordo com os usuários, a sonolência dificultava, também, a execução das atividades diárias fora da instituição.

Avaliamos que a não participação nas oficinas terapêuticas, dispositivos, tão importantes quanto as consultas médicas, implica uma redução da potência da proposta terapêutica do serviço. As oficinas terapêuticas se constituem como significativos espaços promotores de cuidado, permitindo a expressão e ampliação das possibilidades individuais bem como a constituição de laços de cuidado consigo e de afetividade com o outro (Guerra, 2008). Essa situação demanda atenção na organização do cronograma terapêutico do CAPS, que precisa se comprometer com a reabilitação social, relacionada com a ampliação do poder contratual dos usuários (Saraceno, 2001), e a Atenção Psicossocial, em que o saber biomédico é apenas uma das matrizes.

No que tange ao comprometimento da memória, os usuários constantemente relatavam o incômodo de não lembrar acontecimentos de sua história de vida, o que lhes geravam ansiedade e angústia. Associavam a falta de memória ao uso da medicação psicotrópica:

Oh fia, por que será que eu não me lembro das coisas? Tem hora que eu fico perdidinha no tempo mesmo...vou fazer as coisas e esqueço...que dia é hoje mesmo? Tem hora que eu fico tentando lembrar das coisas, mas não consigo! Acho que deve ser esses remédios...tu acha o quê? (Fragmento da fala de usuário registrada em diário de campo).

Outro efeito colateral enfatizado foi a diminuição da libido, principalmente pelos homens. Todavia, o que chama atenção refere-se à maior dificuldade em relação à aceitação desse efeito colateral em comparação aos demais, que eram vistos com mais naturalidade. A questão da impotência sexual é algo que os mobiliza, causando incômodo. Destacamos que tal queixa era frequentemente exposta durante a imersão em campo. 
Vou the ser sincero, que pra relação o bicho deixa o cabra mei fraco! Eu conversei com o doutor, ele disse que é por causa dos remédios. Ele conversou com a mulher também, que essa impotência sexual é por causa do medicamento que eu tomo, que é muito forte. Ela achava que eu tinha outra mulher, que eu não procurava ela, mas eu vi que ela tá consciente, porque o médico conversou com ela, por causa dos remédios (Usuário 8).

Cordás e Laranjeiras (2006) destacam que o efeito da medicação sobre a função sexual é considerado um dos mais problemáticos, pois se configura em uma importante razão para a não adesão ao tratamento com psicofármacos. No entanto, era um tema até pouco tempo negligenciado, quando comparado aos outros efeitos acima citados. Compreendemos que merece especial atenção, pelo grau de incômodo a ele relacionado.

De modo geral, percebeu-se que os efeitos adversos estimulam o abandono ao tratamento, como afirma Zago (2009) e, com frequência, a mudança da medicação por conta própria, comprometendo ainda mais o andamento do processo de cuidado. Isso se revela no relato abaixo:

O medicamento, com a dosagem que o médico passou... Não tava me sentindo muito bem. Eu peguei e mudei. Ele tava dando muita tremura no corpo, porque eu tenho um problema de nervo também. Eu dei uma mudada nele. Não tinha como ter minhas atividades físicas no trabalho mesmo (Usuário 4).

Apesar de os usuários focarem seu relato nos efeitos físicos do uso da medicação, alguns fragmentos narrativos apontam para repercussões psicossociais do uso medicamentoso, dentre as quais destacam-se: o preconceito, a falta de oportunidade de trabalho e a incompreensão da família. Também em estudo de Jorge, Onocko-Campos, Pinto e Vasconcelos (2012), as narrativas dos usuários se apresentaram carregadas de sentidos e significados relativos à convivência com a comunidade, à interação com outros usuários, com a família e a equipe de saúde.

Percebemos que muitos fragmentos narrativos, como o que segue abaixo, expressam uma carga de preconceito intensa sofrida pelos usuários, em função do uso desse tipo de medicação:

Eu era outra pessoa! Eu sinto assim, que hoje eu não sou mais que nem eu era, porque quem toma remédio controlado não é mais o que ele era, mais nunca! [..] O encarregado viu eu tomando o remédio. Ele perguntou que remédio era, eu disse: Diazepam. Ele disse: Vixi, você é doido, é? Eu disse: Não, é pro sistema nervoso que o médico passou. Quando foi um dia, eu tava trabalhando (...), chegou uma moto: Quem é R aqui? Eu disse: Sou eu! A moça disse: O senhor tá sendo dispensado do emprego. Perguntei: O que foi que eu fiz? Ela disse: Você não fez nada; o senhor tem que procurar tratamento, porque tá tomando Diazepam, não pode ficar trabalhando em cima do pé de manga tomando Diazepam, não! (Usuário 3).

Podemos notar que o estigma da "doença mental" ainda domina as representações construídas pela sociedade, a respeito de usuários de medicamento psicotrópico, caracterizando tais sujeitos por aquilo que mais desejam superar: a condição de apresentar um transtorno mental, como indicado por Jorge et al. (2012).

Eu sou Mórmon, batizado na igreja tem quatro anos, e isso tem me ajudado bastante de lá pra cá. Mas as pessoas lá não me aceitam como eu sou, não. É tanto que restringe para assumir os cargos da igreja, assim como eu tive grande preconceito na época quando eu tava trabalhando (Usuário 2).

Jorge e Bezerra (2004) salientam a necessidade de questionar e romper tais estereótipos, superando a concepção de que a doença fundamenta a identidade social do sujeito. Os autores destacam que a sensação de rejeição, quase sempre, está associada a sentimentos como falta de amor, desvalorização, perda da autoestima, frustração e depreciação da autoimagem. Assim, compreendemos a desconstrução de rótulos atribuídos à "doença mental", esta própria um rótulo, crucial para que se avance na perspectiva da legitimação de modos outros de estar no mundo. O estigma relacionado à pessoa diagnosticada com transtorno psíquico dificulta o convívio social, contribuindo para gerar sentimentos de exclusão e mais sofrimento, como indica o fragmento narrativo a seguir, em que se evidencia uma depreciação da autoimagem: "Quando eu tô em casa, eu não tenho aquele prazer de sair pra conversar com ninguém. Fico só mais deitado. Eu me sinto assim... Parece que eu sou desprezado pelo povo. Me sinto doente." (Usuário 3).

Atrelado a esse sentimento de desvalorização social, destaca-se a relação com o trabalho como um dos pontos sempre presentes nos depoimentos dos usuários. Muitos, depois do diagnóstico, além do preconceito experienciado, vivenciaram duas situações: a 
dificuldade de conseguir emprego ou demissões por conta do problema. Não fica difícil compreender que tal fato interfere diretamente na autonomia e autoestima desses sujeitos, afetando sua capacidade de se sentirem produtivos, como ressalta um dos interlocutores, ao ser questionado sobre as possíveis interferências da medicação no seu cotidiano:

Impede, principalmente, de trabalhar. Começou assim: tem oito anos que eu tô sem trabalhar. Ela impede, porque o seguinte, o encarregado quando vê que a pessoa toma o Diazepam, ele já rejeita a pessoa, me botaro pra fora. [...] Também, depois fiquei trabalhando particular. Nem botei na justiça, porque eu não gosto disso aí. Aí fiquei vindo pro CAPS, mas procurando serviço, mas o fuxico era que o meu problema já tava no computador, que eu tinha aquele problema. [...] Eu trouxe os exames do Piauí, minha mulher anda direto com eles aí, o exame e o atestado. A assistente social viu e disse: 'o senhor tem esses papel e não apresentou a nois ainda na triagem? Pois você não pode trabaIhar mais não' (usuário 3).

No Brasil existem políticas públicas de saúde mental, respaldadas na Lei $10.2016 / 2001$, que destacam, dentre os direitos das pessoas com transtorno mental, o de serem tratadas com dignidade e respeito, no interesse exclusivo de beneficiar sua saúde, visando alcançar sua recuperação pela inserção na família, no trabalho e na comunidade. Essas políticas visam à inserção social e promoção da autonomia dos sujeitos diagnosticados com transtorno psíquico. Contudo, o estigma social atrelado a essa condição dificulta seu processo de reabilitação psicossocial.

Outro aspecto evidenciado foi a importância do apoio familiar no processo saúde-doença dos usuários. Contudo, revelou-se uma dificuldade da família em assumir essa função, como pode ser visto nos fragmentos a seguir: "Minha família fica me dizendo que eu tomo medicação porque eu quero, que não sabe pra que eu fico tomando esses remédios, que eu gosto de viver dopada!" (Usuário 9). "A família não deixa a gente sair na rua, não quer que a gente saia só, porque tem medo que a gente se perca [...] Eu antigamente já dei vontade de suicidar" (Usuário 3).

Segundo K. V. L. G. Silva (2010), a família deve ser entendida como uma unidade de cuidado, fazendo-se presente nesse processo saúde/doença e tendo papel significativo na promoção do cuidado ao sujeito em sofrimento psíquico. Quando esse cuidado não se constitui, favorece-se a fragilidade dos vínculos estabelecidos pelos usuários, tanto no convívio familiar como nas suas relações sociais como um todo.

Desse modo, os depoimentos revelaram movimentos polarizados dos familiares: da desvalorização da experiência de sofrimento à superproteção e infantilização do sujeito com transtorno psíquico. Em meio a isso, sobressai a falta de apoio, de compreensão e, possivelmente, a dificuldade de lidar com esses sujeitos, o que indica a necessidade de apoio à família para que esta possa exercer uma função de suporte ao usuário de forma efetiva.

As reflexões acima remetem à segunda dimensão, relativa à necessidade de uma atuação terapêutica sensível à singularidade do usuário, que parta de suas compreensões em relação às repercussões que o uso da medicação tem em suas experiências e seus modos de viver.

\section{A Importância da Atuação Terapêutica Sensível à Singularidade do Usuário}

De acordo com Lucchese, Oliveira e Marcon (2009), nos últimos anos o cenário da saúde mental vem se configurando em um processo complexo de transformação, pautando-se em saberes e práticas que buscam superar o modelo biomédico de caráter medicalizante e hospitalocêntrico.

Através dos dispositivos de atenção comunitária, substitutivos à lógica asilar, coloca-se o sujeito em sofrimento psíquico no foco da ação, por meio de uma práxis transformadora, em constante construção. Onocko-Campos et al. (2013) defendem que nos serviços substitutivos as estratégias de cuidado precisam estar além do medicamento e das psicoterapias, englobando ações no campo da moradia, do trabalho assistido, lazer e cultura, promovendo saúde de forma legítima e eficaz.

Impõe-se, assim, a necessidade de pôr em prática um saber/fazer fundamentado na Atenção Psicossocial, que ultrapassa os princípios hegemônicos da racionalidade biomédica. Os processos terapêuticos, tal como pudemos experienciar em campo, não levam em conta a singularidade do sujeito, na maioria dos casos.

O medicamento interferiu na rotina no começo, que a dose do Levozine era maior. Eu tomava de noite, aí passava o dia grogue, sem condições de fazer nada. E a instrução do médico era que eu não podia fazer nada mesmo! (Usuário 6).

Em um cenário de hegemonia das práticas biomédicas, a relação médico-usuário acaba ganhando 
destaque; entretanto, a instituição de modos substitutivos de cuidado em Saúde Mental vai na contramão disso. Como salienta Luiz (2005), tendo como fundamento os princípios da biomedicina, essa relação tende a se deteriorar com a objetivação dos usuários e a mercantilização dessa relação, na qual o "paciente" é visto como um consumidor de bens médicos e que, se não for curado, deve ter ao menos seu sofrimento aliviado.

Em contraponto, é fundamental entender que o cuidado hoje precisa acontecer pelas muitas mãos de uma equipe de profissionais, que posicione o usuário no centro do processo. Sobretudo em um contexto de CAPS, essa equipe precisa questionar quaisquer idealizações do que é "ser saudável", valorizando os usuários como protagonistas de sua vida e processo terapêutico.

Nessa direção, Pereira et al. (2010) enfatizam o respeito à singularidade e o favorecimento ao diálogo, na relação equipe-usuários, possibilitando-se que estes se sintam apoiados em seus processos existenciais. Para tanto, é necessário que os profissionais não se limitem às dimensões técnicas e prescritivas, apreciando a realidade de cada usuário e contribuindo para que o vínculo, entre os atores envolvidos, seja estabelecido no cotidiano dos serviços: "Depois que mudou a dosagem do Levozine - antes era $100 \mathrm{mg}$, depois foi pra 50, agora tá 25 - me sinto bem melhor, consigo mais fazer as coisas" (Usuário 6). "Eu me sinto bem, porque realmente aqui tem umas pessoas que se importam com a gente!" (Usuário 2).

"Aqui no CAPS, me ajuda muito. Participo dos grupos. Hoje eu não participei, porque ainda tô mei doido da queda que levei" (Usuário 4).

Percebemos que quando a comunicação é estabelecida na relação profissional/usuário, este tem a possibilidade de negociar o caminho a ser traçado para o seu cuidado - inclusive a medicação mais adequada. Se há falta de diálogo, isso reflete diretamente no processo terapêutico, repercutindo no modo como o usuário pode conduzir o tratamento, gerando, por vezes, sentimento de angústia, como ilustra o fragmento seguinte:

\footnotetext{
"Hoje um dos usuários, que havia conversado individualmente comigo alguns dias atrás, me abordou fazendo o seguinte questionamento: Quando eu falei com você naquela entrevista sobre o remédio, você falou com o médico? Porque eu queria que você falasse com ele sobre a mudança que eu fiz na medicação pra vê o que ele diz" (Fragmento de diário de campo).
}

Em campo, dentre os atores envolvidos - profissionais, usuário, familiares -, o médico era referido pelos usuários, constantemente, como de difícil acesso ao diálogo. Os usuários nem sempre recebem informações e orientações sobre seu tratamento, sendo os médicos, nesse contexto, a figura central e o detentor da autoridade, como indicam Onocko-Campos et al. (2013).

Avaliamos que, a partir da abertura ao diálogo, é possível que os usuários ressignifiquem o valor do medicamento em seu tratamento, admitindo sua relevância na redução dos sintomas específicos à patologia, mas reconhecendo também a importância de outros subsídios terapêuticos nesse processo, o que é fundamental. Assim, vias para a superação de práticas medicalizantes surgem, através de ações que vão para além da consulta médica, perpassando por práticas intersetoriais, grupais, educativas e sanitárias, como apontam Jorge et al. (2012).
A medicação é importante, porque ela impede a gente de fazer besteira. Às vezes dava vontade de surrar eu mesmo, de brigar com o povo na rua, e a outra coisa que é muito importante pra pessoa é a psicóloga [...] Aí de mim se não fosse o CAPS! (Usuário 3).
Mesmo com a medicação, tem 14 anos que eu faço tratamento, mas eu continuo... Não sinto vontade de sair pra lugar nenhum, não me sinto bem em lugar que tem muita gente. [...] Tenho medo do escuro, de ficar sozinha e, principalmente, que eu fico vendo vultos e vozes, eu fico com medo! (Usuário 9).

Nesse sentido, acentua-se a responsabilidade terapêutica do serviço de saúde, que não deve se restringir à figura do médico. É imprescindível que o trabaIho aconteça em equipe, em articulação e comunicação contínua com usuários e familiares, que precisam ser enfatizados como protagonistas. É fundamental que essa equipe amplie suas possibilidades de cuidado e reflita sobre como se relaciona com a hegemonia do saber biomédico: compreendemos que o modo de agir da equipe pode reforçar essa hegemonia entre os usuários.

Por esta via, pode-se promover a ampliação do poder de contratualidade nos diversos cenários da vida dos usuários, seja em casa, no serviço de saúde ou na sua rede social (Saraceno, 2001), possibilitando, assim, o estabelecimento de estratégias para promoção da autonomia do sujeito. Sendo o trabalho no CAPS complexo, 
devido à demanda de constantes arranjos que facilitem a aproximação entre os profissionais, usuários e território (Miranda \& Onocko-Campos, 2010) e intenção de favorecer a construção de vínculo entre usuários e profissionais, exige um saber-fazer com base nas relações cotidianas que atravessam a vida do usuário.

Outro ponto importante remete à definição diagnóstica, aspecto constantemente observado no discurso dos usuários. De acordo com R. S. Silva e Brandalise (2008), quando o sujeito é percebido como "doente mental", ele acaba se identificando com o diagnóstico e com os atributos a ele ligados, como indica o fragmento abaixo:

Hoje o que me chamou atenção foi o fato de o usuário sempre carregar consigo um laudo médico plastificado como uma carteira de identidade. Conversou comigo sobre o seu problema, em seguida retirou o laudo da bolsa, como prova do que estava dizendo (Fragmento do diário de campo).

Percebemos uma falta de cuidado no momento em que esse diagnóstico é apresentado ao usuário e, até mesmo, a falta de um olhar mais sensível da equipe sobre esse processo de investigação/definição diagnóstica. Destacamos a importância de o usuário ter a sua singularidade respeitada, sendo visto além do seu diagnóstico. Como indicam Jorge et al. (2012), abordar o sujeito de forma singular promove uma melhora significativa no seu estado de saúde, possibilitando que o diálogo se estabeleça, de modo produtivo. Produzir novos sentidos à utilização do medicamento, no contexto de um processo terapêutico mais amplo, é necessário, possibilitando que usuários possam compartilhar experiências entre si, tendo acesso a outras possibilidades terapêuticas, que não se limitam ao uso do medicamento.

Destacamos que, de acordo com as narrativas dos usuários, eles, em geral, atribuíam uma avaliação positiva ao CAPS, contudo, tal avaliação estava diretamente relacionada ao tratamento medicamentoso recebido, como aponta a narrativa abaixo:

Ai de mim se não fosse o Caps! O povo fala que aqui no CAPS não tem remédio, pelo menos um ou dois têm, mas pior quem vive pelos posto. Mas se não fosse vocês, que é psicólogo, que orienta a gente, e o CAPS que desse remédio, esses dois, ai de nois. Se fosse só pelos postos, porque os postos de hoje em dia não querem dar mais aquela receita pra comprar o diazepam não. [...] Eu só quero dizer que, eu peço a Deus que esse CAPS melhore mais, que venha mais remédio, que eu fui obrigado a comprar o remédio! (Usuário 3).

Assim, percebemos a necessidade de superar a supremacia da racionalidade biomédica, presente ainda nos dispositivos substitutivos, e que parece ser reproduzida, por toda a equipe, nas relações com os usuários. Como apontam Onocko-Campos et al. (2013), apesar dos avanços alcançados com a Reforma Psiquiatra no Brasil, a medicalização da sociedade ainda continua como uma prática não reformada.

\section{Considerações finais}

Pelo estudo, compreendemos que a medicação ocupa posição de destaque no processo terapêutico de usuários de um serviço substitutivo, estratégico; que estes estabelecem uma relação ambivalente com o uso do medicamento, de forma que percebem a medicação de modo positivo, quando atua na remissão dos sintomas, e de modo negativo, no que tange aos efeitos colaterais indesejáveis, além de efeitos psicossociais, tais como o preconceito, vivenciado nos mais diversos contextos, provocando ainda mais sofrimento.

Podemos apontar, portanto, algumas consequências biopsicossociais como: dependência, comprometimento da memória, diminuição da libido, sono excessivo, tremores e dificuldade de reinserção social que o uso da medicação pode provocar na vida dos sujeitos, sobretudo em seus modos singulares de viver. Tais consequências, se compreendidas tendo como pano de fundo o contexto da medicalização da sociedade contemporânea, demandam reflexões permanentes das equipes terapêuticas.

A partir das dimensões discutidas anteriormente, propomos reflexões e reposicionamentos sobre o processo saúde/doença. De acordo com Soares e Camargo Jr. (2007), isso implicaria defender o fortalecimento das relações profissionais-usuários e entre os usuários e sua família, consideradas fundamentais para o cuidado no âmbito da saúde mental/atenção psicossocial. Para isso, é imprescindível reconhecer o usuário como ser único, singular e pertencente a um contexto social. Quando há o fortalecimento dessas relações, no processo de cuidado do usuário, sua forma de experienciar o tratamento acontece de forma mais significativa e eficaz, legitimando-o como protagonista nesse processo, via potente de empoderamento.

Sugerimos um repensar sobre as compreensões e modos de fazer utilizados nos serviços substitutivos, que 
deveriam focar no processo de ampliação do poder contratual. Compreendemos que as equipes dos CAPS contribuem para a fragilização de sua potência terapêutica ao colocarem, em seu agir terapêutico, o medicamento na posição central. Essa é uma via para a institucionalização ou cronificação dos usuários. Cabe que o medicamento seja um dentre os vários recursos terapêuticos disponíveis. Importa que os CAPS invistam na diversificação de estratégias de cuidado, repensando o uso do medicamento e instituindo práticas que favoreçam esse processo emancipatório do usuário. A centralidade de medicamentos, nos projetos terapêuticos, pode sugerir um sutil mecanismo de controle, respaldando-se na análise foucaultiana das relações entre poder/verdade/ disciplina.

Em sintonia com o pensamento de Guarido (2007), não pretendemos, com as compreensões produzidas no estudo, simplesmente criticar o uso dos psicofármacos, mas certamente reposicioná-lo no rol das ferramentas terapêuticas, evidenciando os efeitos desse uso a partir de um discurso de medicalização e banalização da vida.

O aprofundamento de tal questão pode contribuir de forma significativa, especialmente para reflexões sobre a atuação de profissionais de saúde mental e as práticas terapêuticas adotadas nos serviços de saúde. Se o compromisso de um processo terapêutico é impactar os modos de fazer a vida andar, pelos usuários, torna-se crucial que os profissionais extrapolem o intuito de controle, muitas vezes, incorporado nas prescrições medicamentosas e outras práticas terapêuticas, fortalecendo a promoção da autonomia e/ou empoderamento dos sujeitos.

Assim, compartilhamos da afirmação de Soares e Camargo Jr. (2007), de que a autonomia merece ser promovida como uma condição de saúde e cidadania, tendo um valor fundamental para a vida do sujeito. Importa, portanto, pôr em questão a supremacia da lógica biomédica, que tem na utilização do medicamento, voltado à cura - ortopédica -, um dos princípios fundamentais.

No intuito de levar a discussão à frente, encerramos sublinhando o desafio do cuidado em saúde mental/atenção psicossocial: a urgência de perceber e lidar com sujeitos, valorizando sua condição existencial, respeitando seu modo de estar no mundo e investindo em uma rede de cuidado e atenção que ultrapasse muros institucionais e ideológicos. Trata-se de um caminho árduo e sem receitas, aberto à inventividade, porém, compromissado com a expansão da vida.

\section{Referências}

Bezerra, I. C., Jorge, M. S. B., Gondim, A. P. S., Lima, L. L., \& Vasconcelos, M. G. F. (2014). Fui lá no posto e o doutor me mandou foi pra cá: processo de medicamentalização e (des)caminhos para o cuidado em saúde mental na Atenção Primária. Interface: Comunicação Saúde e Educação, 18(48), 61-74. doi: 10.1590/1807-57622013.0650

Bezerra, I. C., Morais, J. B., Paula, M. L., Silva, T. M. R., \& Jorge, M. S. B. (2016). Uso de psicofármacos na atenção psicossocial: uma análise à luz da gestão do cuidado. Saúde em Debate, 40(110), 148-161. doi: 10.1590/0103-1104201611011

Caponi, S. (2009). Biopolítica e medicalização dos anormais. Physis Revista de saúde Coletiva, 19(2), 529-549. doi: 10.1590/ S0103-73312009000200016

Caponi, S. (2012). Loucos e degenerados - uma genealogia da psiquiatria ampliada. Rio de Janeiro: FIOCRUZ.

Caponi, S. (2014). O DSM-V como dispositivo de segurança. Physis: Revista de Saúde Coletiva, 24(3), 741-763. doi: 10.1590/ S0103-73312014000300005

Carvalho, A. L., Costa, M. R., \& Fagundes, H. (2006). Uso racional de psicofármacos (Vol. 1, pp. 1-6). Subsecretaria de Ações e Serviços de Saúde: coordenação de programas de Saúde Mental, Rio de Janeiro. Recuperado de http://www.ensp.fiocruz.br/portal-ensp/ judicializacao/pdfs/289.pdf

Conrad, P. (1992). Medicalization and social control. Annual Review of Sociology, 18, 209-232. Recuperado de http://www.jstor.org/ stable/2083452

Cordás, T. A., \& Laranjeiras, M. (2006). Efeitos colaterais dos psicofármacos na esfera sexual. Revista de Psiquiatria Clínica, 33(3), 168173. doi: 10.1590/S0101-60832006000300007

Dantas, J. B. (2009). Tecnificação da vida: uma discussão sobre o discurso da medicalização da sociedade. Fractal: Revista de Psicologia, 21(3), 563-580. doi: 10.1590/S0101-60832006000300007

Dutra, E. (2002). A narrativa como técnica de pesquisa fenomenológica. Estudos de Psicologia, 7(2), 371-378. doi: 10.1590/ S1413-294X2002000200018

Ferrazza, D. A., Luzio, C. A., Rocha, L. C., \& Sanches, R. R. (2010). A banalização da prescrição de psicofármacos em um ambulatório de saúde mental. Paidéia, 20(47), 381-390. doi: 10.1590/ S0103-863X2010000300010

Foucault, M. (1979). Verdade e poder. In M. Foucault (Org.), Microfísica do poder (Cap. 1, pp. 1-14). Rio de Janeiro: Edições Graal.

Gaudenzi, P., \& Ortega, F. (2011). O estatuto da medicalização e impressões de Ivan Illichi e Michael Foucault como ferramentas conceituais para o estudo da desmedicalização. Interface Comunicação, Saúde, Educação, 16(40), 243-256. doi: 10.1590/ S1414-32832012005000020

Guarido, R. (2007). A medicalização do sofrimento psíquico: considerações sobre o discurso psiquiátrico e seus efeitos na Educação. Educação e Pesquisa, 33(1), 151-161. doi: 10.1590/ S1517-97022007000100010

Guerra, A. M. C. (2008). Oficinas em saúde mental: percursos de uma história, fundamentos de uma prática. In M. C. Costa \& A. C. 
Figueredo (Orgs.), Oficinas terapêuticas em saúde mental: sujeito, produção e cidadania (pp. 23-58). Rio de Janeiro: Contra Capa.

Jorge, M. S. B., \& Bezerra, M. L. M. R. (2004). Inclusão e exclusão social do doente mental no trabalho: representações sociais. Texto \& Contexto de Enfermagem, 13(4), 551-558. doi: 10.1590/ S0104-07072004000400007

Jorge, M. S. B., Onocko-Campos, R., Pinto, A. G. A., \& Vasconcelos, M. G. F. (2012) Experiências com gestão autônoma da medicação: narrativa de usuários de saúde mental no encontro dos grupos focais em centros de atenção psicossocial. Physis: Revista de Saúde Coletiva, 22(4), 1543-1561. doi: 10.1590/ S0103-73312012000400015

Kastrup, V. (2009). O funcionamento da atenção no trabalho do cartógrafo. In E. Passos, V. Kastrup \& L. Escóssia (Orgs), Pistas do método da cartografia: pesquisa-intervenção e produção de subjetividade (pp. 32-51). Porto Alegre: Sulina.

Lucchese, R., Oliveira, A. G. B., Conciani, M. E., \& Marcon, S. R. (2009). Saúde mental no Programa Saúde da Família: caminhos e impasses de uma trajetória necessária. Cadernos de Saúde Pública, 25(9), 2033-42. doi: 10.1590/S0102-311X2009000900017

Luiz, M. T. (2005). Cultura contemporânea e medicinas alternativas: novos paradigmas em saúde no fim do século $X X$. PHYSIS: Revista de Saúde Coletiva, 15, 145-176. doi: 10.1590/ S0103-73311997000100002

Luiz, M. T., \& Barros, N. F. (Orgs.) (2012). Racionalidades médicas e práticas integrativas em saúde: estudos teóricos e empíricos. Rio de Janeiro: UERJ; IMS; LAPPIS.

Miranda, L., \& Onocko-Campos, R. (2010). Análise das equipes de referência em saúde mental: uma perspectiva de gestão da clínica. Cadernos de Saúde Pública, 26(6), 1153-1162. doi: 10.1590/ S0102-311X2010000600009

Neto, P. P., \& Caponi, S. (2010) Medicalização, revisitando definições e teorias. In C. D. Tesser (Org), Medicalização social e atenção à saúde no SUS (pp. 35-51). São Paulo: Hucitec.

Onocko-campos, R., \& Gama, C. A. (2008). Saúde mental na atenção básica. In G. W. S. Campos \& A. V. P. Guerreiro (Orgs), Manual de práticas de atenção básica: saúde ampliada e compartilhada (pp. 210-236). São Paulo: Hucitec.

Onocko-campos, R. T., Passos, E., Palombini, A. L., Santos, D. V. D., Stefanello, S., Gonçalves, L. L. M., \& Borges, L. R. (2013). A Gestão autônoma da medicação: uma intervenção analisadora de serviços em saúde mental. Ciência \& Saúde Coletiva, 18(10), 2889-2898. doi: 10.1590/S1413-81232013001000013

Organização Mundial de Saúde. (1946). Constituição da Organização Mundial da Saúde (OMS/WHO). Biblioteca Virtual de Direitos Humanos da USP (pp. 1-9). Recuperado de http://www.direitoshumanos.usp.br/index.php/OMSOrganiza\%C3\%A7\%C3\%A3o-Mundial-da-Sa\%C3\%BAde/constituicao-da-organizacao-mundial-da-saude-omswho.html.

Passos, E., \& Barros, R. B. (2009). A cartografia como método de pesquisa-intervenção. In E. Passos, V. Kastrup, \& L. Escóssia (Orgs), Pistas do método da cartografia: pesquisa-intervenção e produção de subjetividade (pp. 17-31). Porto Alegre: Sulina.

Pereira, A. D., Freitas, H. M. B., Ferreira, C. L. L., Marchiori, M. R. C T., Souza, M. H. T., \& Backes, D. S. (2010). Atentando para as singularidades humanas na atenção à saúde por meio do diálogo e acolhimento. Revista Gaúcha de Enfermagem, 31(1), 55-61. doi: 10.1590/S1983-14472010000100008

Rozemberg, B. (1994). O consumo de calmante e o "problema dos nervos" em lavradores. Revista de Saúde Pública, 28(4), 300-308. doi: 10.1590/S0034-89101994000400010

Santos, J. (2012). Consumo excessivo de medicamentos, um problema de saúde pública. RET - SUS, 6(55), 6-9. Recuperado de http:// www.retsus.epsjv.fiocruz.br/upload/55/Retsus_55_EmRede02.pdf

Saraceno, B. (2001). Reabilitação social: uma estratégia para a passagem do milênio. In A. Pitta (Org), Reabilitação psicossocial no Brasil (pp. 13-18). São Paulo: HUCITEC.

Severo, A. K. S.; \& Dimenstein, M. (2009). O diagnóstico psiquiátrico e a produção de vida em serviços de saúde mental. Estudos de Psicologia, 14(1), 59-67. doi: 10.1590/S1413-294X2009000100008

Silva, K. V. L. G. (2010). Cuidado ao familiar de adulto em sofrimento psíquico: desafio para a assistência de enfermagem (Dissertação mestrado). Recuperado de http://www.uece.br/cmacclis/dmdocuments/kely_vanessa.pdf

Silva, R. S., \& Brandalise, F. (2008). O efeito do diagnóstico psiquiátrico sobre a identidade do paciente. Mudanças - Psicologia da Saúde, 16(2), 123-9. doi: 10.15603/2176-1019/mud.v16n2p123-129

Soares, J. C. R. S., \& Camargo Junior, K. R. (2007). A autonomia do paciente no processo terapêutico como valor para a saúde. Interface - Comunicação, Saúde e Educação, 11(21), 65-78. doi: 10.1590/S1414-32832007000100007

Tesser, C. D., \& Barros, N. F. (2008). Medicalização social e medicina alternativa e complementar: pluralização terapêutica do Sistema Único de Saúde. Revista de Saúde Pública, 42(5), 914-920. doi: 10.1590/S0034-89102008000500018

Zago, A. C.(2009). Adesão ao tratamento medicamentoso dos usuários dos CAPS em Pelotas - RS, com transtornos de humor e esquizofrenia (Dissertação mestrado). Recuperado de http://docplayer. com.br/5626741-Adesao-ao-tratamento-medicamentoso-dos-usuarios-dos-caps-em-pelotas-rs-com-transtornos-de-humor-e-esquizofrenia.html 
Uso de medicamentos psicotrópicos e repercussões existenciais para usuários de um CAPS II

Deisiluce Miron Cavalcante, Mestre em Psicologia Social pela Universidade Federal de Sergipe (UFS), é Psicóloga Clínica. Endereço para correspondência: Rua Euclides Gois n ${ }^{\circ} 765$, casa 08. Aracaju - SE. CEP: 49035-310. Telefones de contato:

(74) 9 9977-0515/ (79) 9 9126-6055.

E-mail: deisylucym@hotmail.com

Barbara Eleonora Bezerra Cabral, Doutora em Psicologia pela Universidade Federal do Espírito Santo (UFES), é Docente do Colegiado de Psicologia e Coordenadora da Residência Multiprofissional de Saúde Mental na Universidade Federal do Vale do São Francisco (Univasf). E-mail: barbaraebcabral@gmail.com

Recebido em 01.Jul.16 Revisado em 24.Mai.17 Aceito em 01.Set.17 